\title{
Genistein inhibits stemness of SKOV3 cells induced by macrophages co-cultured with ovarian cancer stem-like cells through IL-8/ STAT3 axis
}

Yingxia Ning ${ }^{1,2+}$, Weifeng Feng ${ }^{2+}$, Xiaocheng Cao ${ }^{4,5}$, Kaiqun Ren ${ }^{4,5}$, Meifang Quan ${ }^{4,5}$, A. C'ken Chang Xu U $^{4,5}$, Yebei Qiu ${ }^{4,5}$, Jianguo $\mathrm{CaO}^{4,5^{*}}$, Xiang $\mathrm{Li}^{3,4,5^{*}}$ and Xin LuO ${ }^{2^{*}}$

\section{Abstract}

Background: Recent studies showed that macrophages co-cultured with ova stem-like cells (OCSLCS) induced SKOV3 cell stemness via IL-8/STAT3 signaling. Genistein (GEN) demonst s chemopreventive activity in inflammation-associated cancers. The present study aimed to examine her and if GEN inhibits the stemness of SKOV3 and OVCA-3R cells induced by co-culture of THP-1 macrophages Dâ S, OV3-derived OCSLCS.

Methods: The co-culture was treated with or without different concentrat ons (10, 20, and $40 \mu \mathrm{mol} / \mathrm{L})$ of GEN for $24 \mathrm{~h}$.

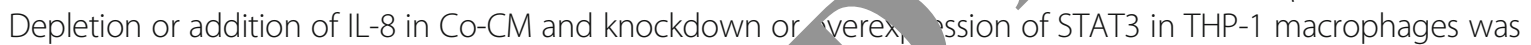
performed to demonstrate the possible associated mechan 5 . Th combined effects of GEN and STAT3 knockdown were examined with the nude mouse modle by co-irjection o. WOV3-derived OCSLCs with THP-1 macrophages.

Results: Our results showed that GEN down-rea (at 16 and p-STAT3 expression of THP-1 macrophage, decreased the levels of IL-10, increased the le of IL- 1 a nitric oxide (NO) in the conditioned medium, and reduced the clonogenic and sphere-formir $\mathrm{Ca}_{\mathrm{a}}$, ities and the expression of CD133 and CD44 in SKOV3 cells induced by co-culture of THP-1 macrophages and QCSLCS a dose-dependent manner. Moreover, depletion or addition of IL8 enhanced or attenuated the effect f GEN. Additionally, knockdown or overepression of STAT3 in THP-1 macrophages potentiated or attenua the inhibitory effects of GEN. Importantly, STAT3 overexpression retrieved the effects of IL-8 combined with GEN depin on M2 polarization of THP-1 macrophages and stemness of SKOV3 cells induced by co-culture. The con in of GEN and STAT3 knockdown cooperatively inhibited the growth of tumors co-inoculated with OCSI S S/THP-1 makrophages in nude mice in vivo through blocking IL-8/STAT3 signaling.

Conclusions: In sum vary, sur finaings suggested that GEN can inhibit the increased M2 polarization of macrophages and stemness of vario ancen cells by co-culture of macrophages with OCSLCS through disrupting IL-8/STAT3

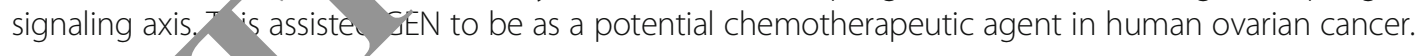

Keywordr- Ovaria ancer, Tumor associated macrophages, Ovarian cancer stem-like cells, Genistein, IL-8/STAT3 axis

* spondence: Caojianguo2005@126.com; 1x58616@163.com;

tluoxe.$c 0 m$

${ }^{+}$Yingxia Ning and Weifeng Feng contributed equally to this work.

${ }^{4}$ Department of Pharmaceutical Science, Medical College, Hunan Normal University, Changsha 410013, China

${ }^{3}$ Department of preclinical medicine, Medical College, Hunan Normal University, Changsha 410013, China

${ }^{2}$ The First Affiliated Hospital of Jinan University, Guangzhou 510632, China

Full list of author information is available at the end of the article

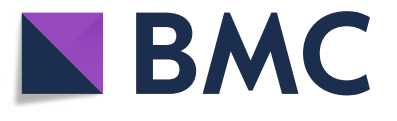

(c) The Author(s). 2019, corrected publication 2021. Open Access This article is distributed under the terms of the Creative Commons Attribution 4.0 International License (http://creativecommons.org/licenses/by/4.0/), which permits unrestricted use, distribution, and reproduction in any medium, provided you give appropriate credit to the original author(s) and the source, provide a link to the Creative Commons license, and indicate if changes were made. The Creative Commons Public Domain Dedication waiver (http://creativecommons.org/publicdomain/zero/1.0/) applies to the data made available in this article, unless otherwise stated. 


\section{Background}

Ovarian cancer is the most frequently diagnosed tumor and lethal gynecological malignancy in the globe. Owing to the non-specific symptoms associated with the disease, most of the ovarian cancer cases are presented with advanced stage disease and lead to high mortality rates $[1,2]$. Despite modest improvements in response rates, progression-free and median survival rates using adjuvant platinum and taxane chemotherapy following cytoreductive surgery, the overall survival rates for patients with advanced ovarian cancer remain disappointing [3, 4]. This is thought to be due to a small subset of cells within the tumor, namely ovarian cancer stem-like cells (OCSLCs) that are resistant to conventional chemotherapy treatments [5]. Current chemotherapy agents aimed on the rapidly dividing cells; however, OCSLCs are not effectively killed by these compounds duo to their slow-division [6, 7]. Therefore, finding and developing a candidate agent that target OCSLCs for the treatment of human ovarian cancer remains important and has clinical implications.

Jackson et al. reported that spheres derived from SKOV3 cells have relatively strong growth potential both in vivo and in vitro compared with the monolayer, indicating that the spheres have the characteristics of OCSLCs [8]. We have recently used stem cell conditioned culture system to obtain the second generation spheres derived from SKOV3 cells, followed by demonstrated the er have the characteristics of cancer stem cells ( $C \mathrm{~s} s$ ), sidering them as SKOV3-derived OCSLCs [, 0$]$. Now adays, the tumor infiltrating inflammatory cells a. nainly considered as tumor associated marrophages ( $1,-\mathrm{Ms}$ ), which play an important role in tum igenesis, cancer invasion and metastasis $[11,12]$. Recent dies have shown that the interaction of TAM a OCSLCS is involved in the occurrence, recurrence and $m \mu_{\text {r }}$ rug resistance of ovarian cancers $[13,141 . \mathrm{r}$ pre ious study showed that THP-1 macrophages o-c 1tured with SKOV3-derived OCSLCs contain ch. cteristics of TAMs [15]. In this study, we thus a the co- alture of THP-1 macrophages and SKOV3-aerive CSLCs to establish an experimental system for interaction, oetween TAM and OCSLCs.

Impor st seral studies have confirmed that signal trar icer dactivator of transcription 3 (STAT3) activaon i. involved in the interaction between CSCs and their n. entumonment, which effectively promoted the char Yrization of CSCs [16-18]. Furthermore, interleukin-8 (IL-8) triggers the activation of STAT3 signaling, which is associated with inflammation, production of reactive oxygen species, ovarian cancer tumorigenesis and multidrug resistance $[19,20]$. Mohamed et al reported that IL-8 secreted from macrophages of patients with inflammatory breast cancer is involved in enhancing migration, invasion and metastasis [21]. Tsuyada et al reported that breast cancer cells secrete multiple cytokines and activate STAT3 induced from breast cancer associated fibroblasts [22]. The study conducted in our laboratory showed that OCSLCs co-cultured with macrophages induced SKOV3 cell stemness via IL-8/STAT3 signaling [15]. These data indicated that blocking IL-8/STAT3 signaling of TAMs can evidently hinder the communic ion between the tumor and the host stromal celis, ing it as a novel therapeutic target for cancer $\mathrm{m}$ cells that mediate the evolution of ova $n$ cancer and other malignant diseases.

Several comparative studies rep rted that t,e levels of soy products and isoflavones we negatively correlated with the incidence of variou ancu culuding ovarian cancer [23-25]. In vitro and in analyses showed that genistein (GEN), an $\mathrm{i} \mathrm{OL}_{\mathrm{L}}$ one cor $\mathrm{Lpound}$ that is derived from legumes and dentate ${ }_{1}$ ts, inhibited oncogenicities in several cance $\mathrm{Ce}_{\text {including }}$ incer stem cell like cells (CSLCs) [26] $~ \mathrm{~V}$ o been reported to display chemopreventive actı in inflammation-associated cancers [27]. Acc oly, we aimed to assess whether and how GEN inhibits thy stemness of ovarian cancer cells induced by co-culturing of THP-1 macrophages and OCSLCs.

\section{Meti ds}

"line and co-culture

Human ovarian cancer SKOV3 and OVCAR-3 cells and numan monocyte THP-1 cells were obtained from the cell bank of Chinese Academy of Sciences (Shanghai, China).

SKOV3 and OVCAR-3 cells were cultured in Dulbecco's modified Eagle's medium (DMEM) with high glucose (Gibco, Grand Island, NY, USA), containing 10\% fetal bovine serum (FBS), $100 \mathrm{IU} / \mathrm{ml}$ penicillin, and $100 \mu \mathrm{g} / \mathrm{ml}$ streptomycin, and then were incubated at $37^{\circ} \mathrm{C}$ in an atmosphere with $5 \% \mathrm{CO}_{2}$. The second generation spheres of SKOV3 cells were obtained using sphere-forming assay, and then were considered as OCSLCs [15].

THP-1 cells were cultured in RPMI-1640 medium (Gibco, USA) supplemented with 10\% FBS (Gibco, USA), $100 \mathrm{IU} / \mathrm{ml}$ penicillin $\mathrm{G}$, and $100 \mu \mathrm{g} / \mathrm{ml}$ streptomycin, and then were incubated in a humidified atmosphere of $5 \% \mathrm{CO}_{2}$ at $37^{\circ} \mathrm{C}$. THP-1 macrophages were induced by phorbol-12-myristate-13-acetate (PMA; final concentration: $100 \mathrm{ng} / \mathrm{ml}$ ) for $24 \mathrm{~h}$. Activated THP-1 macrophages were obtained as previously described [15]. In brief, the THP-1 macrophages $\left(2 \times 10^{6}\right)$ were plated in the lower chamber and cultured for $12 \mathrm{~h}$. Then the SKOV3- and OVCAR-3-derived OCSLCs $\left(2 \times 10^{6}\right)$ were seeded in the upper chamber and co-cultured for $24 \mathrm{~h}$ in transwell system (BD Biosciences, San Jose, CA, USA). After that, the THP-1 macrophages activated OCSLCs in the lower chamber and the supernatant of co-culture (Co-CM) were collected. 


\section{Spheroid formation assay}

SKOV3 and OVCAR-3 cells $\left(2 \times 10^{3}\right)$ were suspended in serum-free DMEM/F12 mixture containing $100 \mathrm{IU} / \mathrm{ml}$ penicillin, $100 \mu \mathrm{g} / \mathrm{ml}$ streptomycin, $20 \mathrm{ng} / \mathrm{ml} \mathrm{hrEGF}, 20$ $\mathrm{ng} / \mathrm{ml} \mathrm{hbFGF}, 0.2 \% \mathrm{~B} 27,0.4 \% \mathrm{BSA}$, and $4 \mu \mathrm{g} / \mathrm{ml}$ insulin (cancer stem cell conditioned medium, CSC-CM) as well as Co-CM ( $v / v: 1: 1)$. The cells were then seeded in an ultra low attachment 6-well plate (Corning Inc., Coring, NY, USA). The total number of tumor spheres was counted after culturing for 8 days. The efficiency of sphere formation was calculated as previously described [15]. Three independent experiments were performed.

\section{Colony formation test}

DMEM medium containing $0.7 \%$ agarose was added into a 6 -well plate. Then, $10^{4}$ SKOV3 and OVACR-3 cells were seeded per well in CSC-CM as well as Co-CM (v/v: 1:1) containing $0.4 \%$ agarose (top layer), and incubated for 3 weeks. Colony count was carried out by using an inverted microscope (Olympus IX53, Japan). Three independent experiments were performed.

\section{Depletion of IL-8 or addition of IL-8}

Co-CM was collected, and was incubated with IL-8 neutralizing antibody (50 nM) (PeproTechInc, USA) for overnight at $4{ }^{\circ} \mathrm{C}$. Then the medium was centrifuged at 12,000 $\mathrm{g}$ for $10 \mathrm{~min}$, and the supernatants were collected $\mathrm{u}$. as conditioned medium for IL-8 immunodepletion. (7lected $\mathrm{Co}-\mathrm{CM}$ was mixed with sterile $10 \mathrm{ng} / \mathrm{A}$ recom, binant human IL-8 (R\&D Systems, USA), and is was considered as the conditioned medium for adding $\mathrm{I}_{\mathrm{f}}-8$.

\section{Adenovirus infection}

THP-1 macrophages $\left(1 \times 10^{5}\right)$ u seeded into 6-well culture plates (Corning Inc.) and incr. $\mathrm{d}$ overnight until they reach $50 \%$ conflue -1 and nfected with adenoviral particles loaded 1 HRad-MCMV-EGFP-STAT3, pHBad-MCMV-FfarP, HBaa-U6-GFP-shSTAT3, and pHBad-U6-GF lasmids (Hanbio Biotechnology Co. Ltd., Shangha, $\mathrm{Ch}_{\mathrm{L}}$ ), respectively. The cells were cultured with Opti-MEN, containing $50.0 \mu \mathrm{L}$ adenoviral particles ( $\mathrm{n}$. ang Biotech Corp) using Enhanced Infection Sol ' on (, igene Co., Ltd., Shanghai, China) for $2 \mathrm{~h}$, nd a er wh.ch, the medium was replaced with DMEM ce anmo 10\% FBS. Infection efficiency was calculated by cour 8 GFP-positive cells and live cells using the same high power field under a fluorescent microscope (Olympus IX53, Japan).

\section{Enzyme-linked immunosorbent assay}

Co-CM was collected from SKOV3- or OVCAR-3-derived OCSLC/THP-1 macrophage co-cultures, centrifuged at $1000 \mathrm{~g}$ for $5 \mathrm{~min}$ to obtain the supernatants, and then assessed for IL-10, IL-12, and IL-8 levels by ELISA with specific kits (Neobioscience, Shenzhen, Guangdong, China) according to the manufacturer's instructions. Absorbance was immediately read at $450 \mathrm{~nm}$ on a microplate reader (BioTek, Winooski, Vermont, USA).

\section{GEN treatment in vitro}

To examine the effects of GEN on co-cultures, TH -1 macrophages co-cultured with SKOV3- or OVCAR- 1,rrved OCSLCs were treated with or without different cono wations of GEN $(10,20$, and $40 \mu \mathrm{mol} / \mathrm{L})$ for $2=$ For de ermining the induced effects of GEN combirced wh tep etion or addition of Co-CM on macrophage olarization nd SKOV3 cell stemness, the THP-1 macrop res and SKOV3 cells were treated with or without 4 con. ned medium from Co-CM depleted IL-8 by keutralı antibody or added recombinant human IL-s, $\mathrm{h}$ he presence or absence of GEN $(10 \mu \mathrm{M})$. To evaluate the lin e between STAT3 activation in THP-1 macropha, $\mathrm{s}$ and GEN treatment in co-cultured THP-1 macrop re SKOV3-derived OCSLCs, the co-culture of $\mathrm{TH}_{\mathbf{H}}$ macrophages expressing STAT3 or STAT3 sh or boch with SKOV3-derived OCSLCs were treated witl $c / w$, nout GEN $(10 \mu \mathrm{M})$.

\section{Wv rn blot analysis}

The $c$ ls were harvested and lysed using ice-cold RIPA lysis (Beyotime Biotechnology, CN). Bradford assay (B.o-Rad Laboratories, Hercules, USA) was used to determine the protein concentration. Equal amounts of protein $(40 \mu \mathrm{g})$ were separated by $10 \%$ sodium dodecyl sulfate-polyacrylamide gel electrophoresis (SDS-PAGE), and then transferred onto a polyvinylidenedifluoride membrane (Millipore, Billerica, USA). The membranes were then blocked with TBST supplemented with 5\% BSA for 2 $\mathrm{h}$ at room temperature, and incubated with primary antibodies against CD133, CD44, CD163 and STAT3 (Abcam, Burlingame, USA, dilution of 1:2000), Nanog and Oct4 (Cell Signaling Technology; Danvers, MA, USA), p-STAT3 (Tyr 705) and $\beta$-actin (Santa Cruz, USA, dilution of 1:2000) for overnight at $4{ }^{\circ} \mathrm{C}$. The membranes were incubated with a horseradish peroxidase-conjugated goat anti-mouse $\operatorname{IgG}$ antibody or goat anti-rabbit IgG antibody (Beyotime Institute of Biotechnology, Shanghai, China) for $1 \mathrm{~h}$. The protein bands were detected using enhanced chemiluminescence kit (Amersham Biosciences, Piscataway, USA).

\section{In vivo tumorigenicity experiments}

Female BALB/c-nude mice (4-5 weeks of age, body weight $12-14 \mathrm{~g}$ ) were purchased from Nanjing Institute of Biomedical Research in Nanjing University. The experimental procedure was performed in accordance with the standard protocols and approved by the Ethics Committee of Hunan Normal University (No. 2015-055) and the Committee of Experimental Animal Feeding and Management (ID: 201607119). 
Mice were acclimated to their new environment for 1 week prior to undergoing the experiment.

To determine that effects of interaction between SKOV3-derived OCSLCs and THP-1 macrophages on the growth of tumors in nude mice in vivo, the mice were injected with SKOV3-derived OCSLCs $\left(1 \times 10^{5}\right.$ cells) in the left flank, and co-injected OCSLCs $\left(1 \times 10^{5}\right.$ cells)/THP-1 macrophages $\left(2 \times 10^{5}\right.$ cells $)$ in the right flank, respectively.

For GEN therapeutic experiments, SKOV3-derived OCSLCs $\left(1 \times 10^{5}\right)$ and THP- 1 macrophages $\left(2 \times 10^{5}\right)$ were mixed with matrigel $(1: 1)$, and then $100 \mu \mathrm{L}$ mixture was injected subcutaneously into each Balb/c-nu mouse. After the xenograft volume achieved about $100 \mathrm{~mm}^{3}$, the mice were randomly divided into 4 groups, with 4 mice in each group. Group 1 mice were given olive oil by gavage and was considered as control group; Group 2 mice were orally given Genistein dissolved in olive oil $(50 \mathrm{mg} / \mathrm{kg})$, once on alternate days, for a total of 10 times; Group 3 mice were intratumorally injected with $20 \mu \mathrm{L}$ per mouse of adenovirus loaded with pHBad-U6-GFP-shSTAT3 (Hanbio Biotechnology Co. Ltd), once a week, for a total of 3 times; and Group 4 mice were orally given Genistein $(50 \mathrm{mg} / \mathrm{kg}$ ) plus injected the adenovirus expressing STAT3 shRNA. Then, the longest (L) and shortest (W) diameters of the subcutaneous xenografts were measured with a Vernier caliper for volame assessment, according to the following formula: $\mathrm{V}$ an planted tumor volume, $\left.\mathrm{mm}^{3}\right)=\mathrm{L} \times(\mathrm{W})^{2} \times 0.5$. A the $\mathrm{d}$ of the experiment, the mice were euthanized and xenografts were weighed after extraction. Xenograft specimens were fixed in $10 \%$ neutral formalin. Tissue sections were submitted to H\&E staining, and the histopathological morphology was evaluated by optical microscopy.

\section{Statistical analysis}

Data were analyzed using SPSS 20.0 for Windo ors Inc., Chicago, USA). All the experiments were re three times and the data were presente $\mathrm{S}$ mea $\mathrm{S} \leq \mathrm{SD}$. Comparisons between the groups for sta ical significance were conducted using a tw -tailed Stuc nt's $t$-test. The differences between multiple roups were analyzed by one-way analysis of varia homogeneity of variance was determ ned, an all, the pairwise comparisons between the $\mathrm{g}$. $\mathrm{ps}$ wer $\mathrm{c}$ analyzed using least significant difference (LS ${ }_{\perp}$ method. Tukey's test was performed in the $\mathrm{nt}$ of incomplete variance of both the control an th erimental groups. Significance was determined $\mathrm{a}_{\star}<0.05$.

\section{Results}

GEN suppre sed M2 polarization of THP-1 macrophages co 'tured with OCSLCs

To a ermine the effects of GEN on M2 phenotype of TP 1 macrophages co-cultured with OCSLCs, the co-culture system of SKOV3-derived OCSLCs/THP-1 macrophages was used. Figure $1 \mathrm{a}$ and $\mathrm{b}$ indicated that

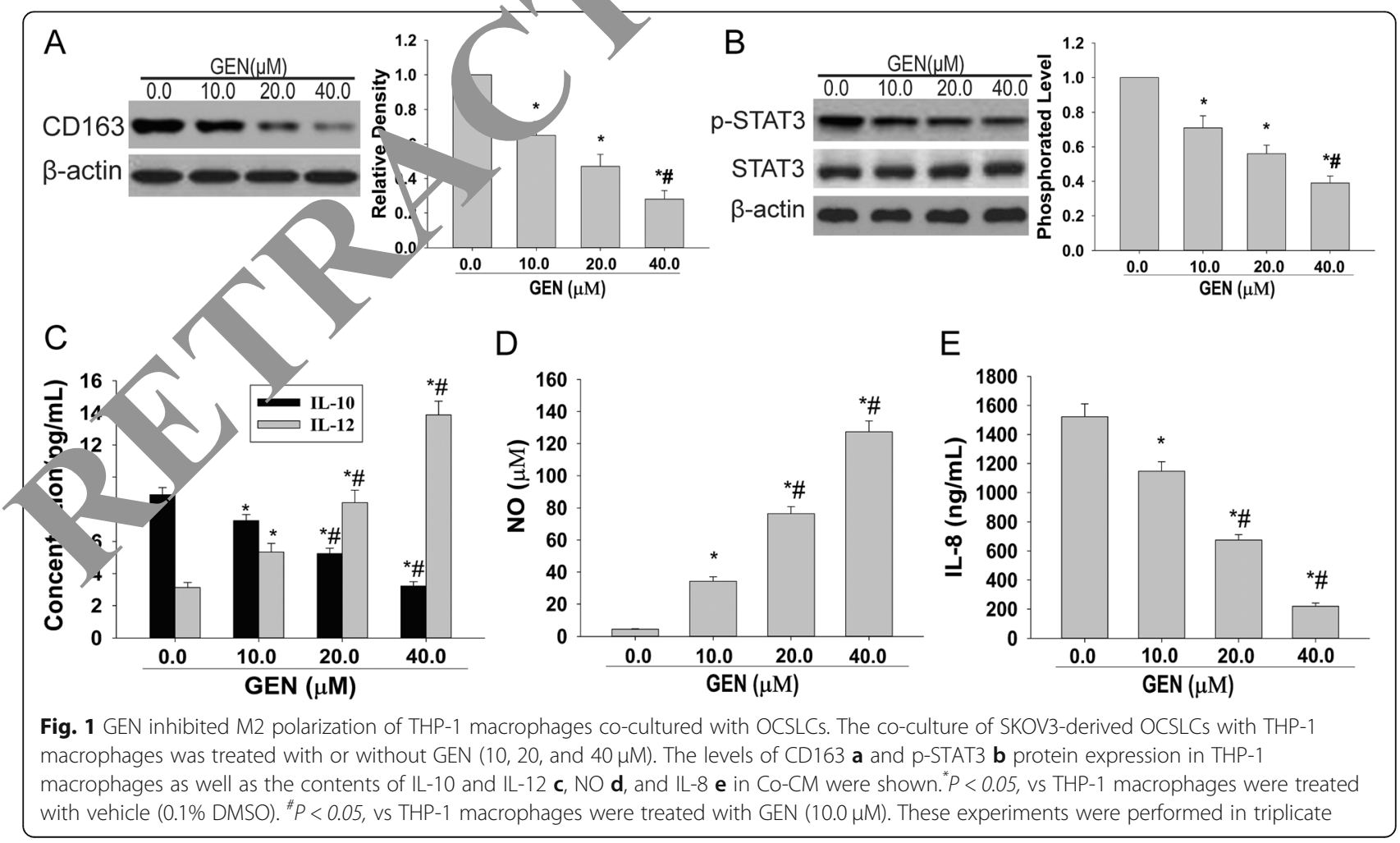


GEN down-regulated CD163 and p-STAT3 expression of THP-1 macrophage, although the expression of STAT3 showed no significant change. In addition, GEN also decreased the levels of IL-10 (Fig. 1c), increased the levels of IL-12 (Fig. 1c) and nitric oxide (NO) (Fig. 1d) in a dose-dependent manner in Co-CM. Furthermore, we found that the levels of IL-8 in Co-CM were reduced by GEN treatment (Fig. $1 \mathrm{e})$. The similarity findings were observed in OVCAR-3-derived OCSLCs/THP-1 macrophages co-culture (Additional file 1: Figure S1). These results suggested that GEN inhibition of M2 polarization might be involved in decreasing IL-8 secretion and inhibiting STAT3 activation in THP-1 macrophages co-cultured with OCSLCs.

\section{GEN alleviated stemness of ovarian cancer cells induced by co-CM}

To assess the inhibitory effects of GEN on ovarian cancer cell stemness induced by co-culture, the Co-CM from the co-culture system of OCSLCs/ THP-1 macrophages treated with or without GEN was obtained. The sphere and colony formation assay revealed that GEN could suppress self-renewal ability (Fig. 2a) and in vitro tumorigenic capabilities (Fig. 2b) in SKOV3 cells induced by Co-CM. Further nore, compared to vehicle (0.1\% DMSO), Co-CM COA ing GEN from the co-culture system signif cantly a creased the protein expression levels $\mathrm{f} \cdot$. cancer stem cell surface markers CD44, CD1 (Fig. and the multipotent transcription fa tors Nanog and OCT4 (Fig. 2d) in SKOV3 cells ir dose-dependent manner. The similarity findings $w$ observed in OVCAR-3 cells induced by C (Additional file 2: Figure S2). These results suggested that GEN could also inhibit the stem ness of ov rian cancer cells induced by Co-CM

Effects of depretion addition of IL-8 combined with GEN on N/2 polarizatis $/$ of THP-1 macrophages induced by co-ce $r$. )

Giv th the GEN inhibits macrophage M2 olar ation co-cultured with OCSLCs and this might b. רvornd in regulating IL-8 secretion, THP-1 macroph treated with depletion or addition of IL-8 $\mathrm{Co}-\mathrm{CM}$ in the presence or absence of GEN was prepared. We found that depletion of IL-8 and GEN together suppressed CD163 and p-STAT3 expression (Fig. 3a and b), but not STAT3 expression in THP-1 macrophages, and reduced IL-10 (Fig. 3c) as well as increased IL-12 (Fig. 3c) and NO (Fig. 3d) in the conditioned medium obtained from THP-1 macrophages treated with IL-8 depletion of Co-CM.

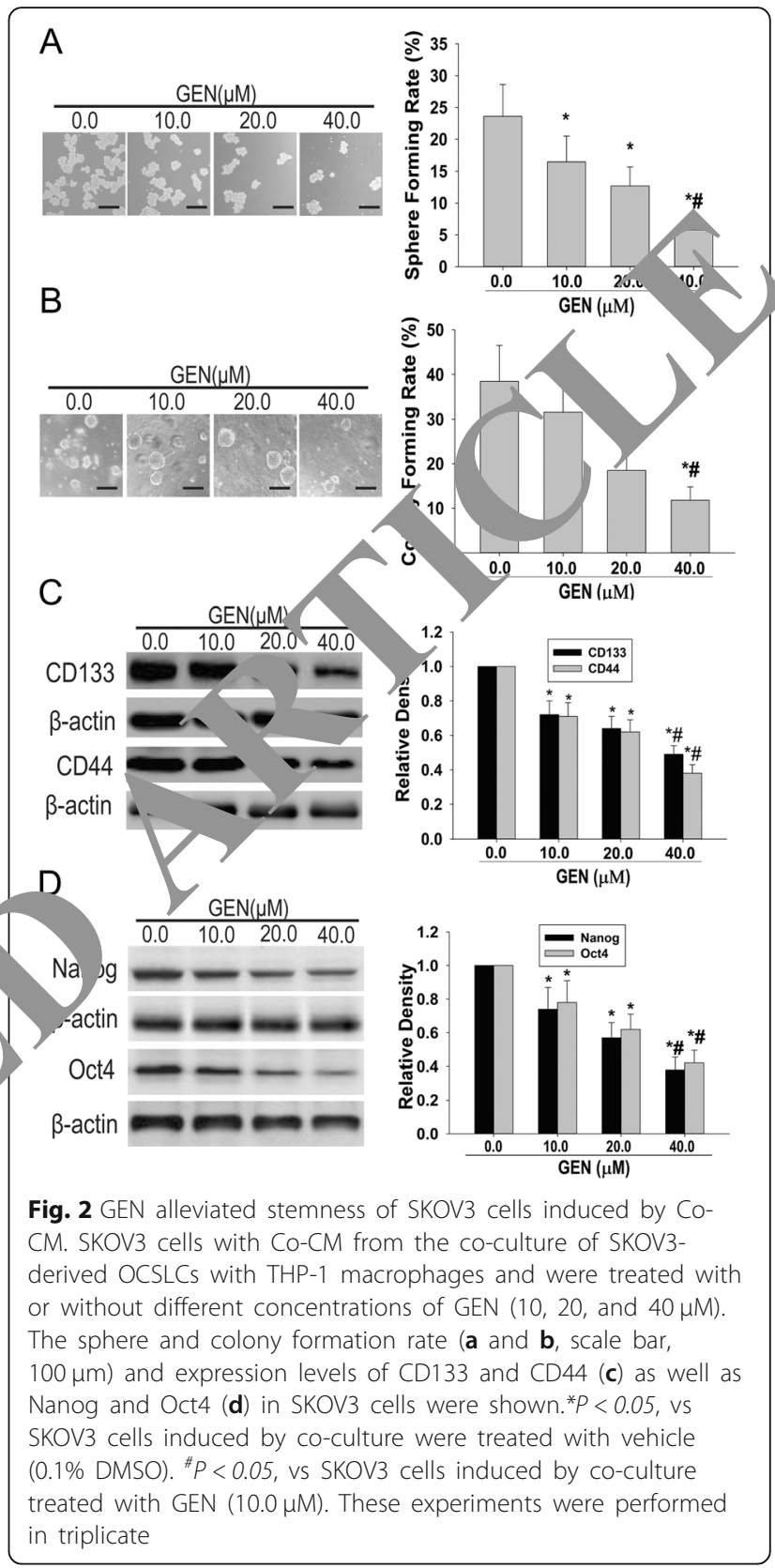

In contrast, addition of IL-8 significantly abolished the inhibitory effects of GEN on CD163 and p-STAT3 expression of THP-1 macrophages (Fig. 3e and f). ELISA analyses revealed the addition of IL-8 addition exhibited antagonistic activity against GEN on IL-10 and IL-12 secretion (Fig. $3 g$ ) as well as NO (Fig. 3h) in the conditioned medium obtained from THP-1 macrophages treated by IL- 8 addition to Co-CM. Together, these findings demonstrated that the inhibitory effect of GEN on M2 polarization of THP-1 macrophages required inhibition of IL-8 secretion caused by co-culture. 


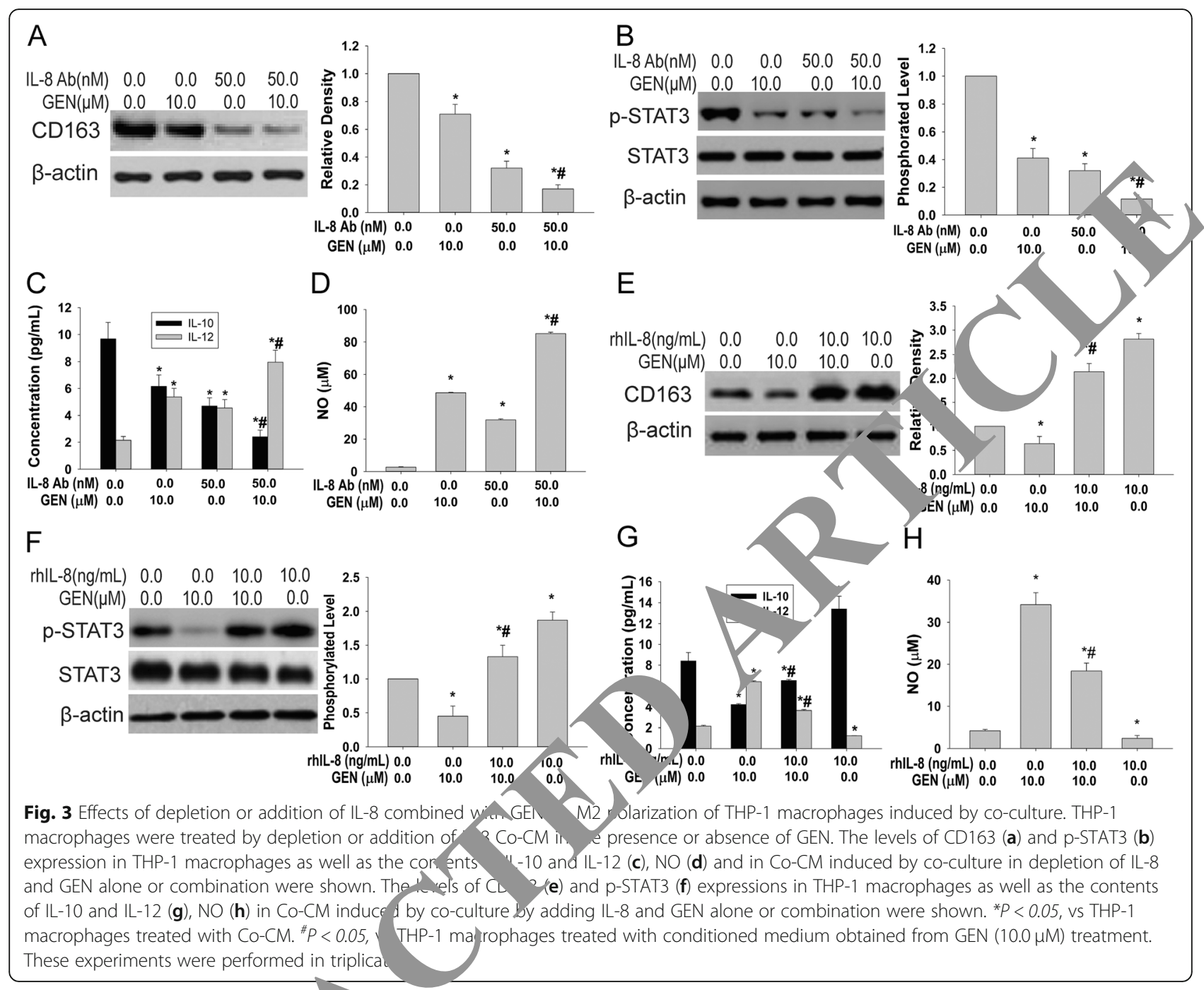

Effects of depletion or a on of IL-8 combined with GEN on stemness of : VV3 - alls ir,duced by co-CM Since GEN could ahib the secretion of IL-8 through co-culture syst, we soug, to investigate whether secretion of IL-8 was in 'ved in the effects of GEN on stemness of SKOV3 celo. The results demonstrated that co-treat $n$ of c'epletion of IL-8 in Co-CM and GEN in co- - 1 ture stem together attenuated the self-renewal bility (Fig. $4 a$ ) and in vitro tumorigenic capabilities (Fig. 4h in Ji. UV3 cells. Furthermore, co-treatment significant. decreased the expression levels of CD44 and CD133 in SKOV3 cells (Fig. 4c). Conversely, the addition of IL-8 significantly neutralized GEN decreased the expression levels of CD44 and CD133 in SKOV3 cells induced by Co-CM (Fig. 4d). Addition of IL-8 effectively opposed the GEN attenuated self-renewal ability (Fig. 4e) and in vitro tumorigenic capabilities (Fig. 4f) in SKOV3 cells induced by Co-CM. Together, these findings suggested that the inhibitory effects of GEN on stemness of
SKOV3 cells are necessary for the inhibition of IL-8 secretion in co-culture system.

\section{Effects of alteration of STAT3 expression combined with GEN on M2 polarization of THP-1 macrophage induced by co-culture}

To explore the role of STAT3 activation in GEN inhibition of M2 polarization of THP-1 macrophages, the THP-1 macrophages expressing STAT3 shRNA were initially used in the co-culture system. STAT3 knockdown and GEN treatment alone down-regulated CD163, STAT3 and p-STAT3 expression in THP-1 macrophages, suggesting the suppression of the above by their combined activity (Fig. 5a and b). In addition, STAT3 knockdown and GEN together reduced IL-10 secretion (Fig. 5c) as well as increased IL-12 secretion (Fig. 5c) and NO (Fig. 5d) in Co-CM. Furthermore, we found that the IL-8 levels (Fig. 5e) in Co-CM in response to GEN treatment was further reduced by STAT3 knockdown. 


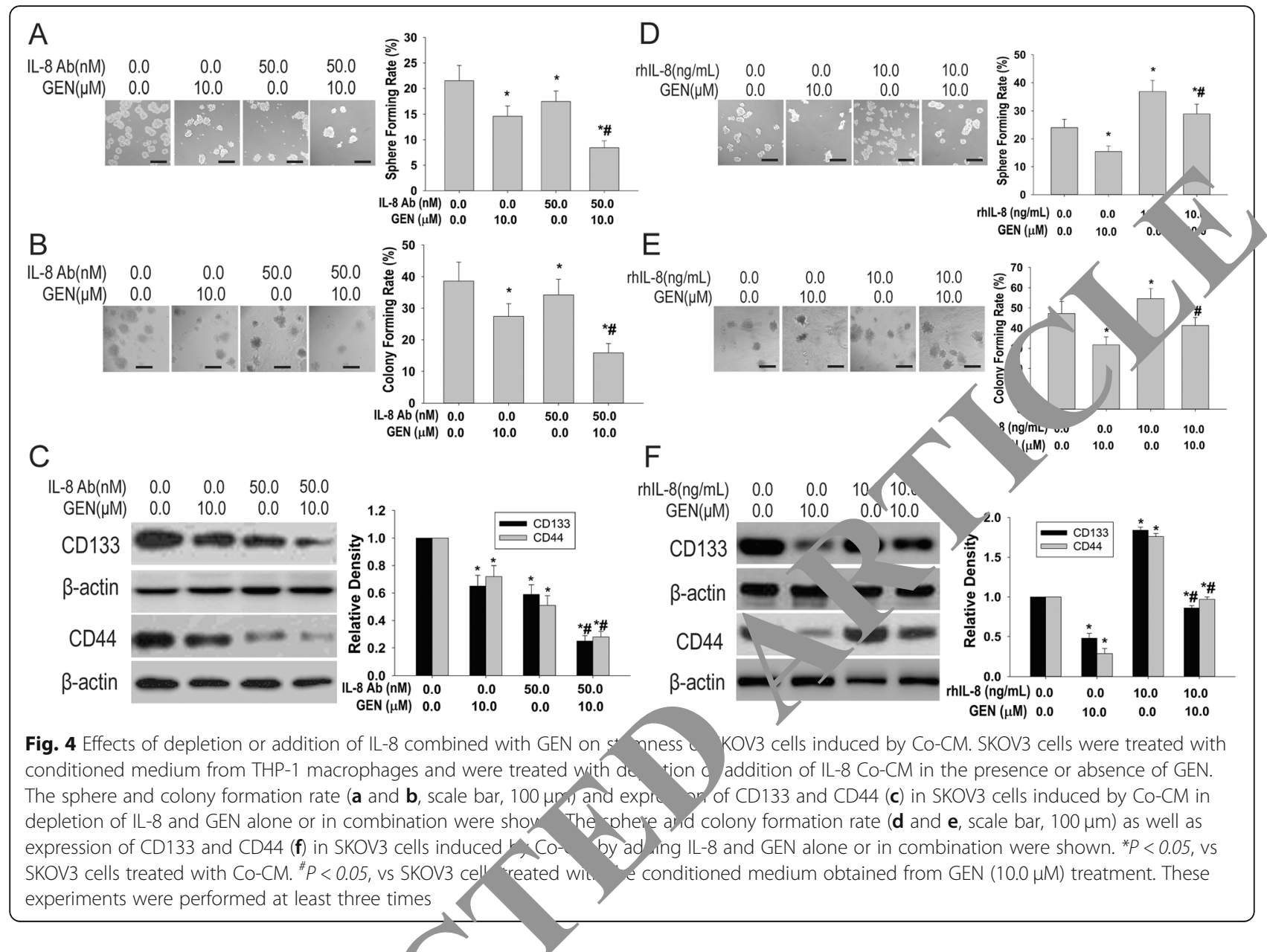

To further identify the role of $S$ AT3 activation in GEN inhibition of $\mathrm{M} 2$ polarization $\mathrm{TH}-1$ macrophages, THP-1 macrophages mressing STAT3 were used in the co-culture system. $Y_{4}$ ata showed that overexpression of STA atten rated GEN suppressed CD163 and p-STAT2 ypr cion in THP-1 macrophages (Fig. $5 \mathrm{f}$ and $\mathrm{g}$ ). In addit overexpression of STAT3 abrogated GEN ro ced IL-1 secretion (Fig. 5h) as well as increased IL- $2 \mathrm{st}$ tion (Fig. 5h) and NO (Fig. 5i) in THP-1 nacrophage: In addition, overexpression of STAT3 ab ogated GEN reduced IL-8 levels in $\mathrm{Co} \sim \mathrm{M}(\mathrm{H}, 5 \mathrm{j})$.

To scertai the role of STAT3 activation in GEN inhibit. Or $1 \mathrm{~L}-$ polarization of THP-1 macrophage induced by co-c are, THP-1 macrophages expressing STAT3 in those expressing STAT3 shRNA were established. Additional file 3: Figure S3A and B depicted that overexpression of STAT3 attenuated STAT3 shRNA combined with GEN suppressed CD163 and p-STAT3 expression in THP-1 macrophages. In addition, overexpression of STAT3 abrogated co-treatment of STAT3 shRNA and GEN reduced IL-10 secretion (Additional file 3: Figure $\mathrm{S} 3 \mathrm{C}$ ) as well as increased IL-12 secretion (Additional file 3:
Figure S3C) and NO product (Additional file 3: Figure S3D) in THP-1 macrophages. Importantly, overexpression of STAT3 significantly antagonized the inhibitory effects of STAT3 shRNA and GEN co-treatment on IL-8 secretion in Co-CM (Additional file 3: Figure S3E). Collectively, these findings demonstrated that the effects of GEN on M2 polarization of THP-1 macrophages are dependent on the inhibition of STAT3 activation of THP-1 macrophages in the co-culture system.

\section{Effects of alteration of STAT3 expression combined with GEN on stemness of SKOV3 cells induced by co-CM}

To investigate the role of STAT3 activation in GEN inhibition of stemness of SKOV3 cells, Co-CM from the co-culture of OCSLCs with THP-1 macrophages expressing STAT3 shRNA was obtained. The results showed that combination of STAT3 knockdown and GEN together attenuated self-renewal ability (Fig. 6a) and in vitro tumorigenic capabilities (Fig. 6b) in SKOV3 cells induced by Co-CM. As indicated in Fig. 6c, combination of STAT3 knockdown and GEN significantly decreased the expression levels of CD44 and CD133 in SKOV3 cells induced by Co-CM. 


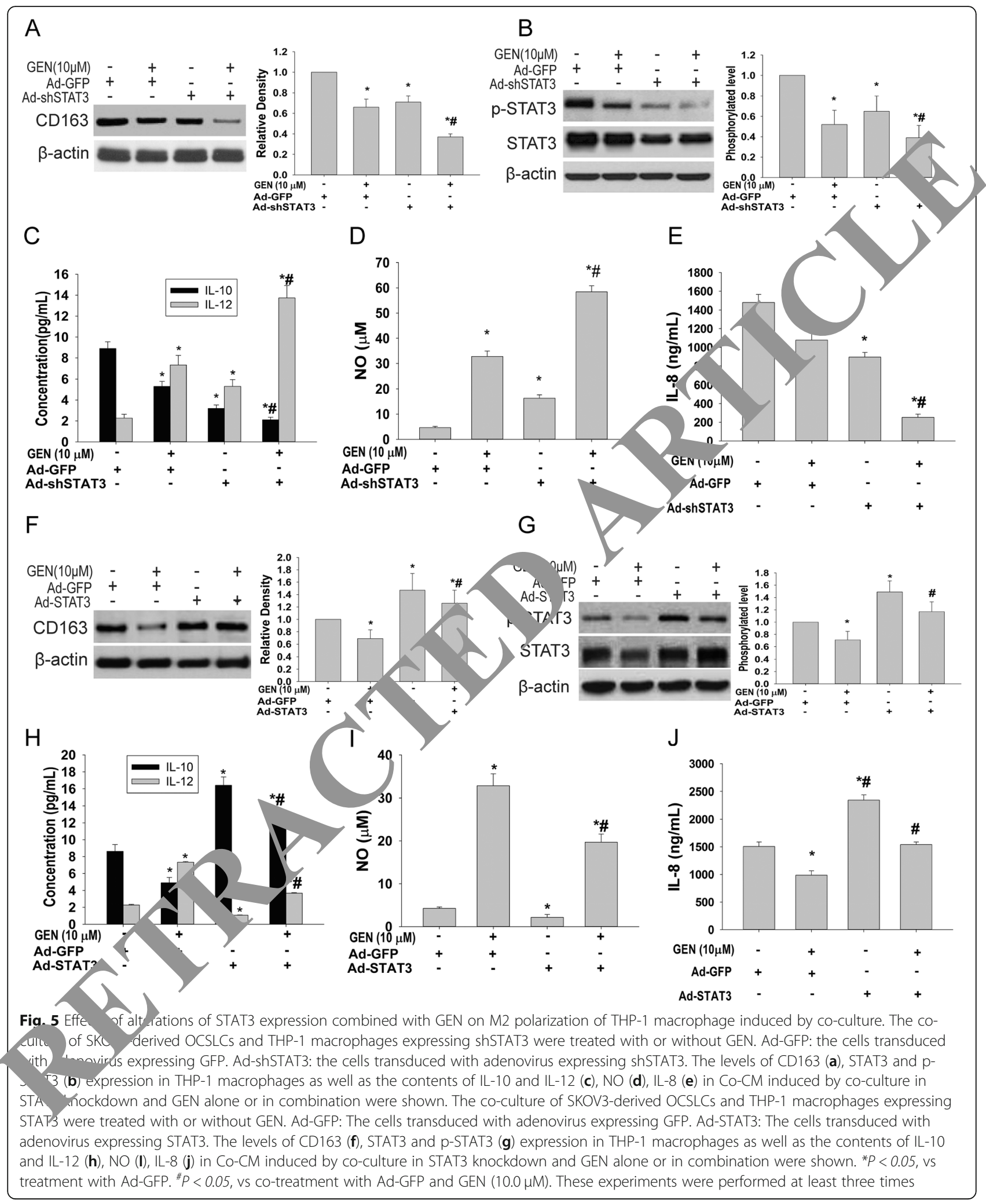

To further examine the role of STAT3 activation in GEN inhibition of stemness of SKOV3 cells, Co-CM from co-culture of OCSLCs with THP-1 macrophages expressing STAT3 was obtained. Figure $6 \mathrm{~d}$ and e indicated that overexpression of STAT3 reduced GEN, which inhibited the self-renewability and in vitro 


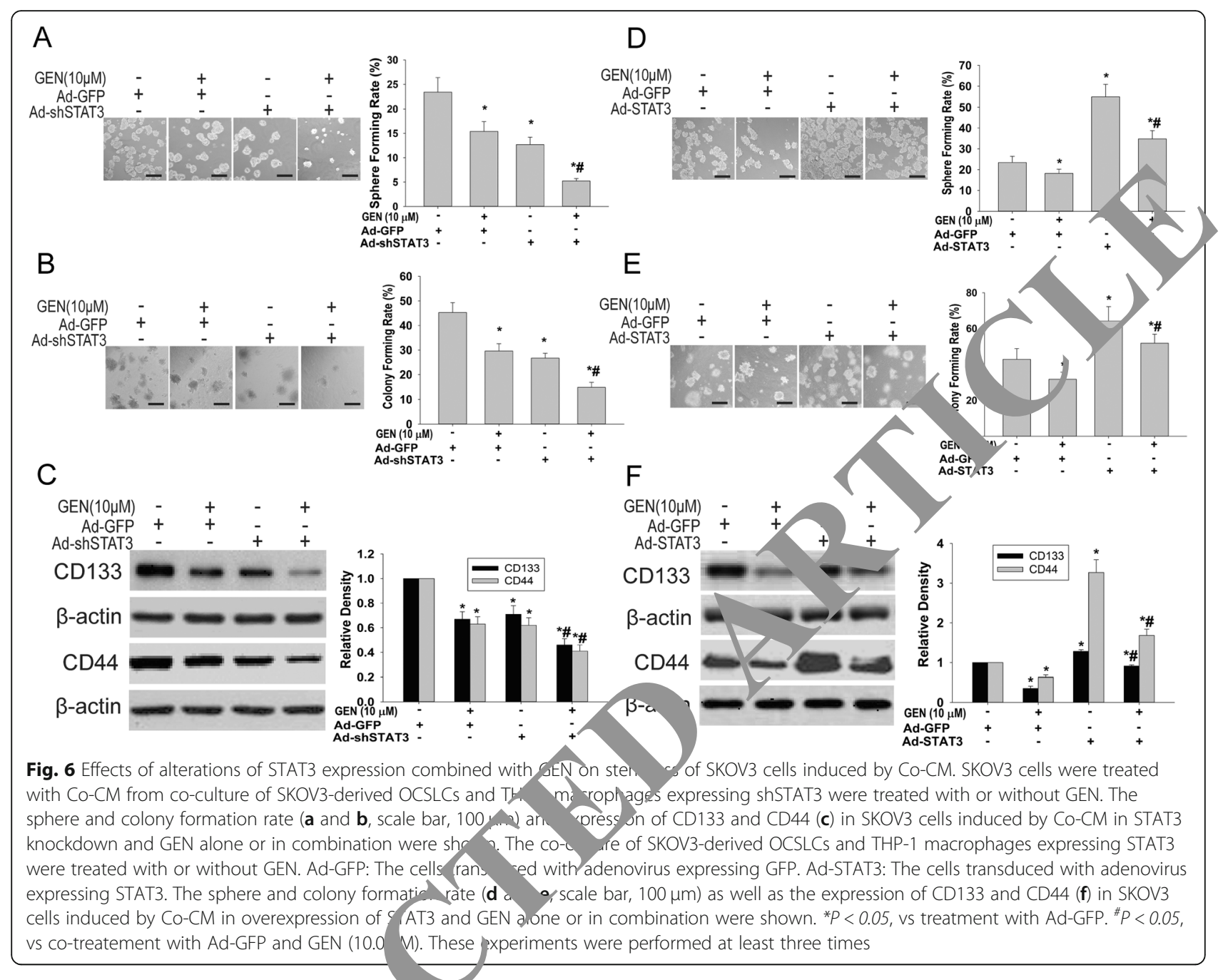

tumorigenic capabilities in $\mathrm{Sl} \mathrm{O}$, cells induced by Co-CM. Overexpressio STA 3 abrogated GEN, decreasing the express le of $\mathrm{CD} 44$ and CD133 in SKOV3 cells indyead b, o-CM (Fig. 6f).

To corrobor the ry of STAT3 activation in GEN inhibition o temness of SKOV3 cells induced by $\mathrm{Co}-\mathrm{C} M$, Co-CM, rom co-culture of OCSLCs with THP-1 1 opl ges expressing STAT3 in those expre-ing $\mathrm{S} T$ ? shRNA THP-1 macrophages was prerea Ove expression of STAT3 reduced STAT3 St "VA combined with GEN, which inhibited the self- éwal ability (Additional file 4: Figure S4A) and in vitro tumorigenic capabilities (Additional file 4: Figure $\mathrm{S} 4 \mathrm{~B}$ ) in SKOV3 cells induced by $\mathrm{Co}-\mathrm{CM}$. As indicated in Additional file 4: Figure S4A, overexpression of STAT3 abrogated STAT3 shRNA combined with GEN decreased the expression levels of CD44 and CD133 in SKOV3 cells induced by co-culture. Collectively, these findings demonstrated that the effects of GEN on stemness of SKOV3 cells are dependent on the inhibition of STAT3 activation of THP-1 macrophages in the co-culture system.

Overexpression of STAT3 rescued the effects of depletion of IL-8 combined with GEN on M2 polarization of THP-1 macrophages induced by co-culture

To clarify whether IL-8/STAT3 axis was involved in GEN inhibition of M2 polarization of THP-1 macrophages, depletion of IL-8 of Co-CM in THP-1 macrophage expressing STAT3 was treated with or without GEN. Figure 7a and b showed that overexpression of STAT3 attenuated depletion of IL-8 combined with GEN, suppressing the expression of CD163 and p-STAT3 in THP-1 macrophages. In addition, overexpression of STAT3 abrogated the depletion of IL- 8 combined with GEN reduced IL-10 secretion (Fig. 7c) as well as increased IL-12 secretion (Fig. 7c) and NO product (Fig. 7d) in Co-CM. In addition, overexpression of STAT3 partly attenuated the depletion of IL-8 combined with GEN decreased IL-8 levels in Co-CM (Fig. $7 \mathrm{e})$. These finding suggested that the effects of GEN on 


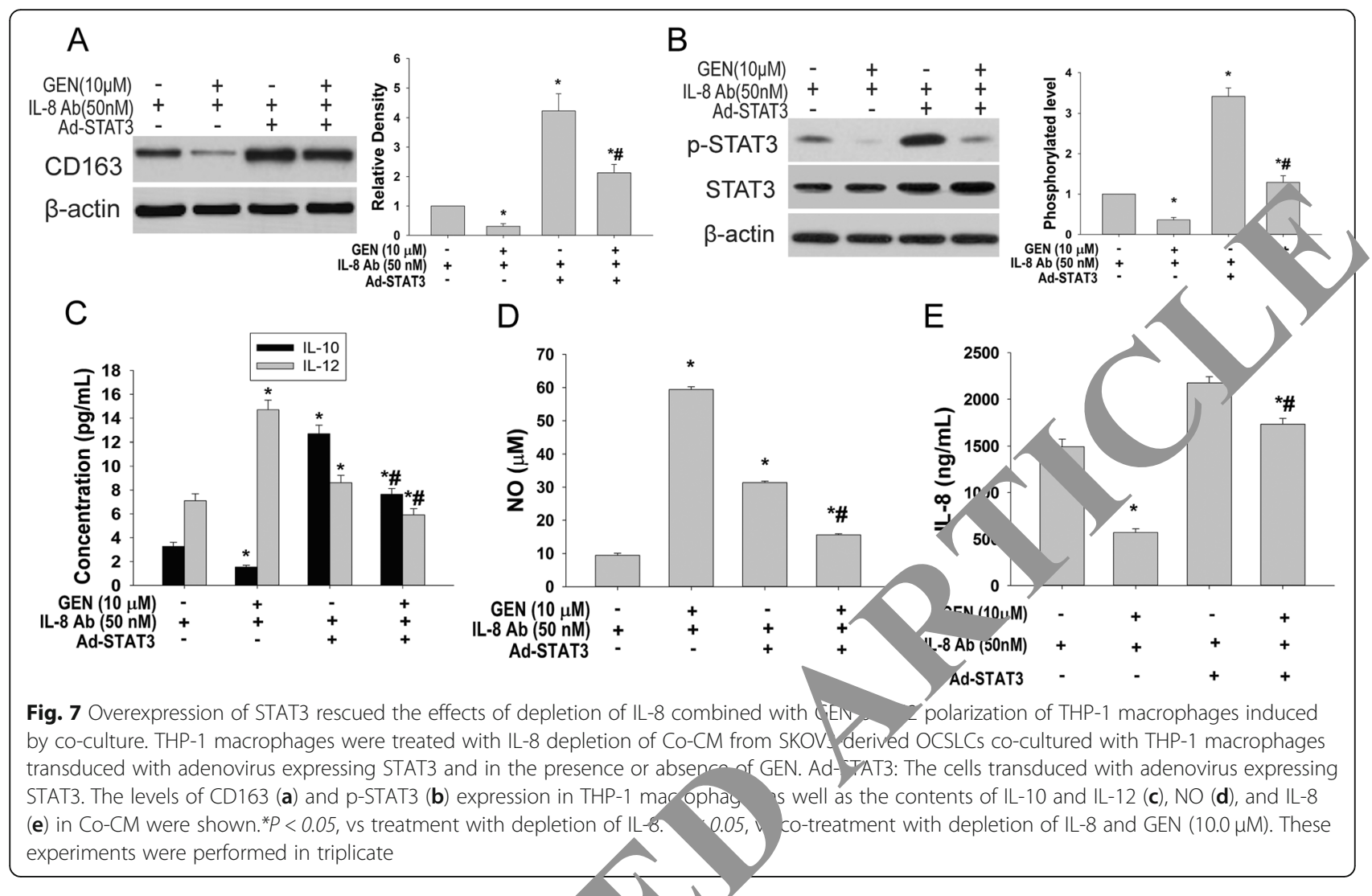

M2 polarization of THP-1 macrophage involved $\mathrm{\nu}$ STAT3 axis in the co-culture system.

Overexpression of STAT3 rescued the ffects of dep etion of IL-8 combined with GEN on stemns s of SKOV3 cells induced by co-CM

To determine the role of IL-8/ $1 \mathrm{~T} 3$ axis in GEN inhibition of stemness of SKOV3 cell 11 a d by Co-CM, depletion of IL-8 of $C 0 \mathrm{M}$ in THP-1 macrophages expressing STAT3 wit or y hout GEN treatment was prepared. As indicater in $\mathrm{Fl}_{\varepsilon}$ ?a, overexpression of STAT3 abrogated the $c$ tion $\mathrm{O}_{1} / \mathrm{L}-8$ combined with GEN decreased the exp, rion levels of CD44 and CD133 in SKOV3 rells induced sy Co-CM. Figure $8 \mathrm{~b}$ and $\mathrm{c}$ showed that or IL-O -1 mb nd i. vitro umorigenic capabilities in SKOV3 cells ina a by $C-C M$. These findings demonstrated that the effects 1 GEN on stemness of SKOV3 cells required modulation of IL-8/STAT3 axis in the co-culture system.

\section{Combination of GEN and STAT3 shRNA cooperatively inhibited xenograft growth by co-injection of SKOV3- derived OCSLCandTHP-1 macrophages}

The results from the nude mouse xenograft model showed that injection with SKOV3-derived OCSLCs alone and co-injection with THP-1 macrophages could form subcutaneous tumors in 30 days; however, the tumor growth by co-injection with OCSLCs/THP-1 macrophages was significantly accelerated than that of injection with OCSLCs alone (Additional file 5: Figure S5A, B and C). Immunohistochemisty revealed elevated human CD68 antigen, IL-8 and p-STAT3 expressions in the co-injected xenografts, compared to OCSLC injection alone (Additional file 3: Figure S3D). These results suggested that the interaction between OCSLCs and THP-1 macrophages promoted the growth of tumors in nude mice in vivo and may be involved in the activation of IL-8/STAT3 signaling pathway.

We also found that GEN plus Ad-STAT3 shRNA reduced the size and weight of xenografts in nude mice co-injected with OCSLCs/THP-1 macrophages (Fig. 9a, b and $\mathrm{c}$ ). The immunohistochemical staining showed that GEN plus Ad-STAT3 shRNA decreased the expression levels of human CD68, IL-8 and p-STAT3 in tumors of nude mice co-injected with OCSLCs/THP-1 macrophages than OCSLCs alone (Fig. 9d). These results demonstrated that GEN inhibits the growth of tumors co-inoculated with OCSLCs/THP-1 macrophages in nude mice in vivo through blocking IL-8/STAT3 signaling.

\section{Discussion}

The present study showed that GEN reduced the levels of IL-8 in Co-CM from OCSLCs co-cultured with 


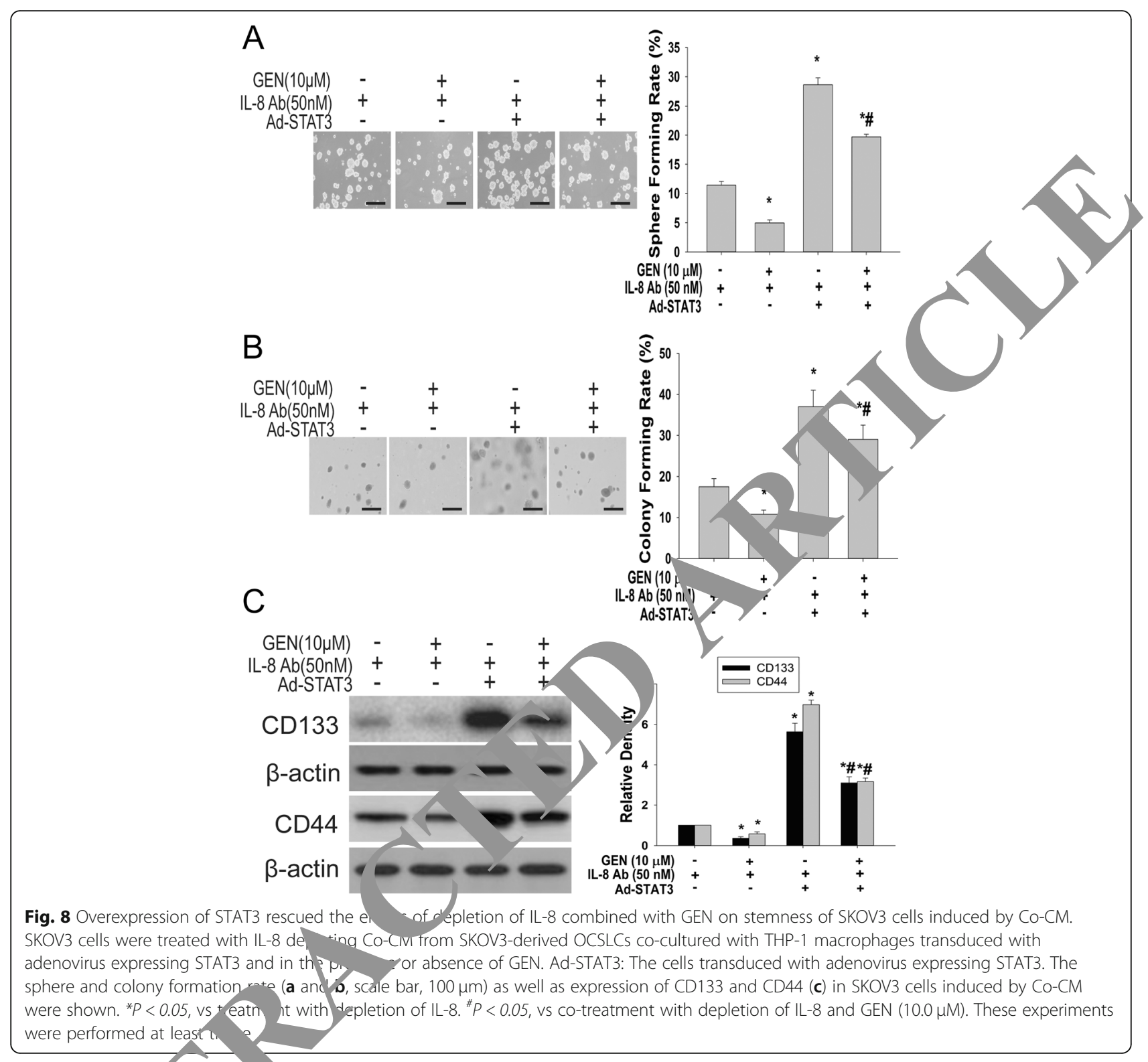

THP-1 macropha and inhibited the expression of CD163 and p-STAT3 in THP-1 macrophages, indicating that GL re rerse M2 polarization of THP-1 macroph M over, GEN suppressed the sphere and colny rmaticn capabilities and significantly decreased t. roun expressions of CD44 and CD133 in ovarian canc cells induced by Co-CM. These results proved that GEN disrupts the interaction of OCSLCs and TAM, inhibits stemness of ovarian cancer cells induced by co-culture. Therefore, the present study strongly supported the notion that interaction of OCSLCs and TAM contributed to carcinogenicity and progression in human ovarian cancer through elevated IL-8 levels in the microenvironment and activated oncogenic transcription factor STAT3 in THP-1 macrophages co-cultured
OCSLCs. This regulation may likely involve the effects of GEN on the prevention and therapy of inflammation-associated cancers, including ovarian cancer.

In addition, activation of IL-8 signal transduction provided tumor cells with chemotherapeutic resistance [28, 29]. IL-8 activates several intracellular signaling pathways in downstream of G-protein-coupled receptor (GPCR) such as CXCR1 and CXCR2 on two kinds of cell surface. The expression of IL- 8 and/or its receptors in tumor cells, endothelial cells, infiltrating neutrophils and TAMs has been significantly increased [30, 31]. Nonetheless, the genetic cells were still not decided, and we herein revealed increased IL- 8 secretion in Co-CM and similarly its IL-8 levels in SKOV3-derived OCSLCs with 


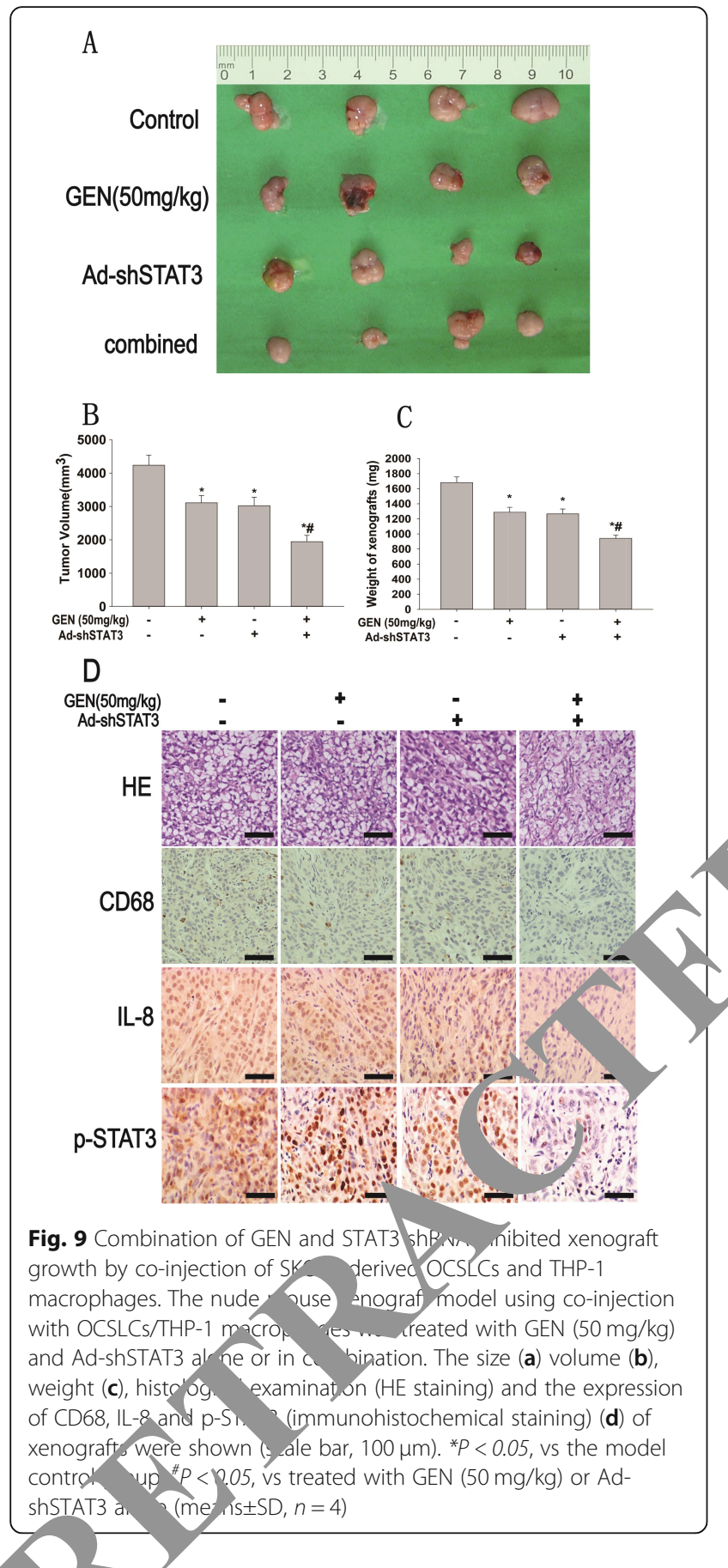

1. -1 mucrophages co-injected xenografts. In addition, we a demonstrated that alterations of IL-8 concentrations in Co-CM significantly affected M2 polarization of THP-1 macrophage and stemness of SKOV3 cells. Therefore, inhibition of IL- 8 signal transduction may be an important therapeutic intervention for targeting tumor microenvironment.

Studies have shown that IL-8 triggers activation of STAT3 signal transduction, which was associated with inflammation, production of reactive oxygen species, tumorigenicity and drug resistance of ovarian epithelial cancer [32-34]. In the present study, we found that knockdown or overexpression of STAT3 in THP-1 macrophages in co-culture system significantly changed the functions that promoted M2 polarization of THP-1 macrophages and stemness of SKOV3 cells inducen by co-culture. Furthermore, alteration of STAT3 gene in THP-1 macrophages could change the levels $\mathrm{O}_{4} \mathrm{~T}_{-\mathrm{O}}$ Co-CM. Given that the STAT3 activation of either 2 s or TAMs was regulated by varied factors, vestige tion of STAT3 activation in response to crivitines, her notactic factors, and other signaling mo ecules stin,alation in tumor microenvironment is conce ble.

Study by Green et al. wea anN analogs $\mathrm{N}$-t-boc-Daidzein is used as a ne ompound for inducing ovarian CSC apopt os confirmed that a nove synthetic GEN analogue 7-difluoromethokyl- :-di-n-sctylgenistein (DFOG) effectively inhibitea cewal ability of SKOV3-derived OCSLCs [9, 36]. h he current study, we initially provided the eviden hat GE $N$ effectively inhibited M2 polarization of THP-1 n.cro, hages and stemness of SKOV3 cells induced by $\mathrm{o}$-culture. Mechanistically, inhibition of M2 Po. ration of THP-1 macrophages and stemness of SKOV3 cells ight be involved in the modulation of secretion of a $\mathrm{h}$ Co-CM and STAT3 activation in THP-1 macrophages in SKOV3-derived OCSLCs and THP-1 macrophage co-culture system. Since IL-8 triggers the activation of STAT3, it is involved in the interaction of tumor microenvironment and CSCs, and can effectively promote the characteristics of CSCs [37, 38]. It is likely that GEN may exert chemoprevention efficacy in several inflammation-associated cancers, not only in ovarian cancer.

Our recent study showed that co-culture of OCSLCs with macrophages induced ovarian cancer cells stemness via IL-8/STAT3 signaling in vitro [15]. Notably, the results observed in the present study proved that the growth velocity of xenografts from co-injection of SKOV3-derived OCSLCs/THP-1 macrophages in nude mice was faster than that of the injection of SKOV3-derived OCSLC alone in vivo. More importantly, we demonstrated that co-administration of GEN by gavage and Ad-STAT3 shRNA by intratumoral injection significantly reduced the growth of xenografts by co-injection with OCSLCs/THP-1 macrophages. Therefore, combination of GEN and other STAT3 inhibitors should be a promising and useful therapeutic schedule against inflammation-associated ovarian cancers.

Increasing evidence has revealed the major contribution of TAM in the regulation of stemness of CSLCs through different networks of cytokines, chemokines and growth factors. In these processes, TAM interact with and promote stemness of CSLCs via releasing of milk-fat globule-epidermal growth factor-VIII (MFG-E8) and IL-6 through coordinated 
activation of the STAT3 and sonic hedgehog pathways [39]. Interestingly, CSLCs are the major subpopulation driving the production of MFG-E8 and IL-6 from macrophages, suggesting that mediators specifically regulated by CSLCs confer macrophages with the ability to promote the generation of tumorigenic factors such as MFG-E8 and IL-6. In return, expansion of CSLC pool lead to stemness maintenance, and immune modulation within tumor microenvironments $[40,41]$. In the previous and current studies, we showed the interplay between OCSLCs and TAM accelerates tumor progression through IL-8/STAT3 autocrine positive-feedback mechanisms [15]. Our data provide insight to the molecular interplay between CSLCs and TAMs for inflammation-related human ovarian cancers.

\section{Conclusions}

In conclusion, our study clearly demonstrated that GEN disrupts the interaction between OCSLCs and THP-1 macrophages via blocking IL-8/STAT3 signal axis, reverses M2 polarization of THP-1 macrophages, and inhibits the stemness of SKOV3 cells in transwell co-culture system and co-injection of OCSLC/THP-1 macrophages in nude mice. Although IL-8 is raised from the origin, the potential of the combination of GEN and other STAT3 inhibitors for anticancer activities in inflammation-associated ovarian cancer animal models requires further investigation. Our findings tha can inhibit the increased M2 polarization or Th 1 macrophages and stemness of ovarian ca 14 cells b co-culture of macrophages and OCSLCs thro disrupting IL-8/STAT3 signaling axis sh uld be unde,lined. This in turn assisted GEN to be as potent jal chemotherapeutic agent in human inflai atio-associated ovarian cancer.

\section{Additional files}

\section{Additional file 1: Fir, ure S1. inhibited M2 polarization of THP-1} macrophages co-c ed with o $\mathrm{Cs}$. The co-culture of OVCAR-3derived OCSLCS vith 1 macrophages was treated with or without GEN $(10,20$ d $40 \mu \mathrm{M})$. levels of CD163 (A) and p-STAT3 (B) protein expression in THP-1 macroy nages as well as the contents of IL-10 and IL12 (C), D D), a IIL 8 (E) in Co-CM were shown. ${ }^{*} P<0.05$, vs THP-1 macrophages $h$ treate $a$ with vehicle $(0.1 \% \mathrm{DMSO}) .{ }^{*} P<0.05$, vs THP-1 pra hages treated with GEN $(10.0 \mu \mathrm{M})$. These experiments were nerfor hed in triplicate. (TIF $32227 \mathrm{~kb}$ )

. Tionar rile 2: Figure S2. GEN alleviated stemness of SKOV3 cells ind by Co-CM. OVCAR-3 cells treated with Co-CM from the COculture of OVCAR-3-derived OCSLCS with THP-1 macrophages and were treated with or without different concentrations of GEN $(10,20$, and $40 \mu \mathrm{M}$ ). The sphere and colony formation rate (A and B, scale bar, $100 \mu \mathrm{m}$ ) and expression levels of CD133 and CD44 (C) as well as Nanog and Oct4 (D) in OVCAR-3 cells were shown. ${ }^{*} P<0.05$, vs OVCAR-3 cells induced by co-culture were treated with vehicle $\left(0.1 \%\right.$ DMSO). ${ }^{\#} P<0.05$, vs OVCAR-3 cells induced by co-culture treated with GEN (10.0 $\mu \mathrm{M})$. These experiments were performed in triplicate. (TIF $24203 \mathrm{~kb}$ )

Additional file 3: Figure S3. Overexpression of STAT3 reversed the cotreatment of STAT3 shRNA and GEN on M2 phenotype of THP-1 macrophages induced by co-culture of THP-1 macrophages expressing Ad-shSTAT3 were transduced with Ad-STAT3 and co-cultured with SKOV3-derived OCSLCS. Ad-shSTAT3: The cells transduced with adenovirus expressing shSTAT3. Ad-STAT3: The cells transduced with adenovirus expressing STAT3. The levels of CD163 (A) and p-STAT3 (B) expression in THP-1 macrophages as well as the contents of IL-10 and IL-12 (C), NO (D), IL-8 (E) in Co-CM were shown. ${ }^{*} P<0.05$, vs treatment with Ad-shSTAT3.

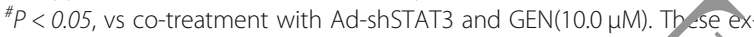
periments were performed in triplicate. (TIF $33896 \mathrm{~kb}$ )

Additional file 4: Figure S4. Overexpression of STAT3 reversed treatment of STAT3 shRNA and GEN on stemness of SKOVZ3 cells ina by Co-CM. THP-1 macrophages expressing Ad-shST/ vere tran duded with Ad-STAT3 and co-cultured with SKOV3-deriv' Oo Ad-s STAT3: The cells transduced with adenovirus expressing shSTAT3. CAT3: The cells transduced with adenovirus expressing TAT3. The sphere and colony formation rate (A and B, scale bar, 100 and expression of CD133 and CD44 (C) in SKOV3 cells were in ed b) cultue. ${ }^{*} P<0.05$, vs treatment with Ad-shSTAT3. ${ }^{*} P<005$, and genistein $(10.0 \mu \mathrm{M})$. These xperimen vere performed at least thrice. (TIF $19091 \mathrm{~kb}$ )

Additional file 5: Figure $\mathbf{5}$. Co- tion with OCSLC/THP-1 macrophages promoted xe ft growth, nude mice. The xenografts in nude mice were o rinate from injection with OCSLCs alone or coinjection with OCS - - Tophages. The size (A), volume (B), weight $(C)$, the histold examination (HE staining) and the expression of CD68, IL and p-STA immunohistochemical staining) (D) in xenograft tissue vo (scale bar, $100 \mu \mathrm{m}) .{ }^{*} P<0.05$, vs injection with OCSLC alone (T, $30,43 \mathrm{~kb})$

\section{Ab. iations}

CSCs: icer stem cells; CSLCs: Cancer stem-like cells; DMEM: Dulbecco's Eagle's medium; FBS: Fetal bovine serum; GEN: Genistein; IL-

8. Reukin-8; L: Longest; LSD: Least significant difference; OCSLCs: Ovarian can_er stem-like cells; SDS-PAGE: Sodium dodecyl sulfate-polyacrylamide gel iectrophoresis; STAT3: Signal transducer and activator of transcription 3;

TAMs: Tumor associated macrophages; W: Shortest

\section{Acknowledgements}

Not applicable.

\section{Funding}

This study was supported by the National Natural Science Foundation of China (No. 81301894, 81302249), Guangzhou Science and Information Bureau Item (No.201300000151) of China, Guangdong Province Department of Science and Technology (No.2014A020211028, 2014A020212609, 2012B031800271) of China, and the scientific research project for Medical College of Bureau of Education of Guangzhou City (No.1201410508). The High-Level Academic Talent Training Program of Guangzhou Medical University ([2017] 210), (B185004083).

\section{Availability of data and materials}

The datasets used and/or analysed during the current study are available from the corresponding author on reasonable request.

\section{Authors' contributions}

YXN, XL. WFF, XCC, KQR. MFQ, AC, CX and YBQ carried out the studies, participated in collecting data, and drafted the manuscript. JGC and XL performed the statistical analysis and participated in its design. All authors read and approved the final manuscript.

\section{Ethics approval and consent to participate}

The experimental procedure was performed in accordance with the standard protocols and approved by the Ethics Committee of Hunan Normal University (No. 2015-055) and the Committee of Experimental Animal Feeding and Management (ID: 201607119). Mice were acclimated to their new environment for 1 week prior to undergoing the experiment.

Consent for publication Not applicable. 


\section{Competing interests}

The authors declare that they have no competing interests.

\section{Publisher's Note}

Springer Nature remains neutral with regard to jurisdictional claims in published maps and institutional affiliations.

\section{Author details}

'Department of Gynaecology and Obstetrics, The First Affiliated Hospital of Guangzhou Medical University, Guangzhou 510120, China. ${ }^{2}$ The First Affiliated Hospital of Jinan University, Guangzhou 510632, China. ${ }^{3}$ Department of preclinical medicine, Medical College, Hunan Normal University, Changsha 410013, China. ${ }^{4}$ Department of Pharmaceutical Science, Medical College, Hunan Normal University, Changsha 410013, China. ${ }^{5}$ Key Laboratory of Study and Discover of Small Targeted Molecules of Hunan Province, Changsha 410013, China.

Received: 24 September 2018 Accepted: 17 December 2018 Published online: 15 January 2019

\section{References}

1. Ayen A, Jimenez Martinez Y, Marchal JA, Boulaiz H. Recent Progress in gene therapy for ovarian Cancer. Int J Mol Sci. 2018;19:E1930.

2. Jessmon P, Boulanger T, Zhou W, Patwardhan P. Epidemiology and treatment patterns of epithelial ovarian cancer. Expert Rev Anticancer Ther. 2017;17:427-37.

3. Lee JY, Kim S, Kim YT, Lim MC, Lee B, Jung KW, et al. Changes in ovarian cancer survival during the 20 years before the era of targeted therapy. BMC Cancer. 2018;18:601.

4. McCormack M. Radiation therapy in ovarian Cancer: an overview and future directions. Clin Oncol (R Coll Radiol). 2018;30:504-6.

5. Condello S, Sima L, Ivan C, Cardenas H, Schiltz G, Mishra RK, et al. Tissue Tranglutaminase regulates interactions between ovarian Cancer stem cells and the tumor niche. Cancer Res. 2018;78:2990-3001.

6. Shibue T, Weinberg RA. EMT, CSCS, and drug resistance: the mechan sic link and clinical implications. Nat Rev Clin Oncol. 2017;14:611-29.

7. Ma J, Salamoun J, Wipf P, Edwards R, Van Houten B, Qian W. of a thioxodihydroquinazolinone with cisplatin eliminates o rian cance stem cell-like cells (CSC-LCS) and shows preclinical poter ala 2018:9:6042-54

8. Jackson TR, Salmina K, Huna A, Inashkina I, Jankevic L, Riekstina U, el DNA damage causes TP53-dependent coupling of self-newal and senescence pathways in embryonal carcinoma cells. Cell Cycl 2013;12:430 41.

9. Ning Y, Luo C, Ren K, Quan M, Cao J. FOXO3a-m ted surpression of the self-renewal capacity of sphere-formind alls deriveamun the ovarian cancer SKOV3 cell line by 7-difluoromet on di-n-octyl genistein. Mol Med Rep. 2014:9:1982-8

10. Ning YX, Li QX, Ren KQ, QuanCao JG. 7-difluoromethoxyl-5,4'-di-n-octyl genistein inhibits ovarian ancer em cell , laracteristics through the downregulation of FOXM . o1 4;8:295-300.

11. Hegab AE, Ozaki M Kagawa S, mamoto J, Yasuda H, Naoki K, et al. Tumor associated macro, res suppory ne growth of FGF9-induced lung adenocarcino a by tiple méchanisms. Lung Cancer. 2018;119:25-35

12. Ma R, Ji T Chen D, Dor ' Zhang $H$, Yin $X$, et al. Tumor cell-derived micror articles polarize $M_{2} /$ tumor-associated macrophages for tumor progr oncoi nmunology. 2016;5:e1118599.

13. Tang $M$, B, , Zhao P. Cross-talk between ovarian cancer cells and n ophage irough periostin promotes macrophage recruitment. Cancer Sci $m 18 \cdot 109.1309-18$

Tan S, Zhou HJ, Ji W, Bellone S, et al. Tumor-associated rophages drive spheroid formation during early transcoelomic merastasis of ovarian cancer. J Clin Invest. 2016;126:4157-73.

15. Ning Y, Cui Y, Li X, Cao X, Chen A, Xu C, et al. Co-culture of ovarian cance stem-like cells with macrophages induced SKOV3 cells stemness via IL-8/ STAT3 signaling. Biomed Pharmacother. 2018;103:262-71.

16. Luo Y, Yang Z, Su L, Shan J, Xu H, Xu Y, et al. Non-CSCs nourish CSCs through interleukin-17E-mediated activation of NF-kappaB and JAK/STAT3 signaling in human hepatocellular carcinoma. Cancer Lett. 2016:375:390-9.

17. Liu H, Ren G, Wang T, Chen Y, Gong C, Bai Y, et al. Aberrantly expressed Fra-1 by IL-6/STAT3 transactivation promotes colorectal cancer aggressiveness through epithelial-mesenchymal transition. Carcinogenesis. 2015;36:459-68.
18. Zhang $\mathrm{CH}, \mathrm{Xu} \mathrm{GL}$, Jia WD, Li JS, Ma JL, Ren WH, et al. Activation of STAT3 signa pathway correlates with twist and E-cadherin expression in hepatocellular carcinoma and their clinical significance. J Surg Res. 2012;174:120-9.

19. Lee JM, Trepel JB, Choyke P, Cao L, Sissung T, Houston N, et al. CECs and IL8 have prognostic and predictive utility in patients with recurrent platinumsensitive ovarian Cancer: biomarker correlates from the randomized Phase-2 trial of Olaparib and Cediranib compared with Olaparib in recurrent platinum-sensitive ovarian Cancer. Front Oncol. 2015;5:123.

20. Stronach EA, Cunnea P, Turner C, Guney T, Aiyappa R, Jeyapa role of interleukin-8 (IL-8) and IL-8 receptors in platinum respo grade serous ovarian carcinoma. Oncotarget. 2015;6:31593-603.

21. Mohamed MM, El-Ghonaimy EA, Nouh MA, Schneider RJ, Sloane Shinawi M. Cytokines secreted by macrophages is microenvironment of inflammatory breast cance? atien chemotactic properties. Int J Biochem Cell P ol. 2014;46:138

22. Tsuyada A, Chow A, Wu J, Somlo G, Chu P bera S, et al CCL2 mediates cross-talk between cancer cells and $s^{+}$(oma roblasts that regulates breast cancer stem cells. Cancer Res. 2012,

23. Bai J, Yang BJ, Luo X. Effects of 5 Arox drox itro-7-propionyloxy-genistein on inhibiting proliferation and in vion via acth 9 reactive oxygen species in human ovarian cancer A2-80/L cells. Oncol Lett. 2018;15:5227-35.

24. Cao X, Ren K, Song Z, Li D, Quan 7heng Y, et al. 7-Difluoromethoxyl-5,4'di-n-octyl genistein .... its the sten rike characteristics of gastric cancer stem-like cells 4 reve as the phenotype of epithelial-mesenchymal transition in gasti. Oncol Rep. 2016:36:1157-65.

25. Ouyang G, Yao L, Ru Kong G, Mao Y, Bao S. Genistein induces G2/M cell cycl ast and ap stosis of human ovarian cancer cells via activation of DNA darm, cell Biol Int. 2009;33:1237-44.

26. Liu Y, Zou T Wang S, Chen H, Su D, Fu X, et al. Genistein-induced differentiati n of breast cancer stem/progenitor cells through a paracrine echanism/int J Oncol. 2016;48:1063-72.

27. ni KA, Rojini G, Rakesh SN, Ratheeshkumar T, Babu MS, Srinivas G, et al. $\mathrm{G} \in$ stein induces apoptosis in ovarian cancer cells via different molecular hways depending on breast Cancer susceptibility gene-1 (BRCA1) status. ur J Pharmacol. 2008;588:158-64.

Krause GC, Lima KG, Haute GV, Schuster AD, Dias HB, Mesquita FC, et al. Fructose-1,6-bisphosphate decreases IL-8 levels and increases the activity of pro-apoptotic proteins in HepG2 cells. Biomed Pharmacother. 2017:89:358-65.

29. Zigler M, Villares GJ, Lev DC, Melnikova VO, Bar-Eli M. Tumor immunotherapy in melanoma: strategies for overcoming mechanisms of resistance and escape. Am J Clin Dermatol. 2008:9:307-11.

30. Attal H, Cohen-Hillel E, Meshel T, Wang JM, Gong W, Ben-Baruch A. Intracellular cross-talk between the GPCR CXCR1 and CXCR2: role of carboxyl terminus phosphorylation sites. Exp Cell Res. 2008;314:352-65.

31. Waugh DJ, Wilson C. The interleukin-8 pathway in cancer. Clin Cancer Res. 2008;14:6735-41.

32. Nguyen $\Pi$, Lian $S$, Ung $\Pi$, Xia $Y$, Han JY, Jung YD. Lithocholic acid stimulates IL-8 expression in human colorectal Cancer cells via activation of Erk1/2 MAPK and suppression of STAT3 activity. J Cell Biochem. 2017;118:2958-67.

33. Zhou J, Yi L, Ouyang Q, Xu L, Cui H, Xu M. Neurotensin signaling regulates stem-like traits of glioblastoma stem cells through activation of IL-8/CXCR1/ STAT3 pathway. Cell Signal. 2014;26:2896-902

34. Seo JH, Jeong KJ, Oh WJ, Sul HJ, Sohn JS, Kim YK, et al. Lysophosphatidic acid induces STAT3 phosphorylation and ovarian cancer cell motility: their inhibition by curcumin. Cancer Lett. 2010:288:50-6.

35. Green JM, Alvero AB, Kohen F, Mor G. 7-(O)-Carboxymethyl daidzein conjugated to N-t-Boc-hexylenediamine: a novel compound capable of inducing cell death in epithelial ovarian cancer stem cells. Cancer Biol Ther. 2009;8:1747-53.

36. Ning $Y, X$ U M, Cao X, Chen X, Luo X. Inactivation of AKT, ERK and NF-kappaB by genistein derivative, 7-difluoromethoxyl-5,4'-di-n-octylygenistein, reduces ovarian carcinoma oncogenicity. Oncol Rep. 2017;38:949-58.

37. Kuo WY, Hwu L, Wu CY, Lee JS, Chang CW, Liu RS. STAT3/NF-kappaBregulated lentiviral TK/GCV suicide gene therapy for cisplatin-resistant triplenegative breast Cancer. Theranostics. 2017;7:647-63.

38. Santoni M, Conti A, Piva F, Massari F, Ciccarese C, Burattini $L$, et al. Role of STAT3 pathway in genitourinary tumors. Future Sci OA. 2015;1:Fso15.

39. Jinushi M, Chiba S, Yoshiyama H, Masutomi K, Kinoshita I, Dosaka-Akita H, et al. Tumor-associated macrophages regulate tumorigenicity and anticancer drug responses of cancer stem/initiating cells. Proc Natl Acad Sci U S A. 2011;108:12425-30. 
40. Scheel C, Eaton EN, Li SH, Chaffer CL, Reinhardt F, Kah KJ, et al. Paracrine and autocrine signals induce and maintain mesenchymal and stem cell states in the breast. Cell. 2011;145:926-40.

41. Naka K, Hoshii T, Muraguchi T, Tadokoro Y, Ooshio T, Kondo Y, et al. TGFbeta-FOXO signalling maintains leukaemia-initiating cells in chronic myeloid leukaemia. Nature. 2010;463:676-80

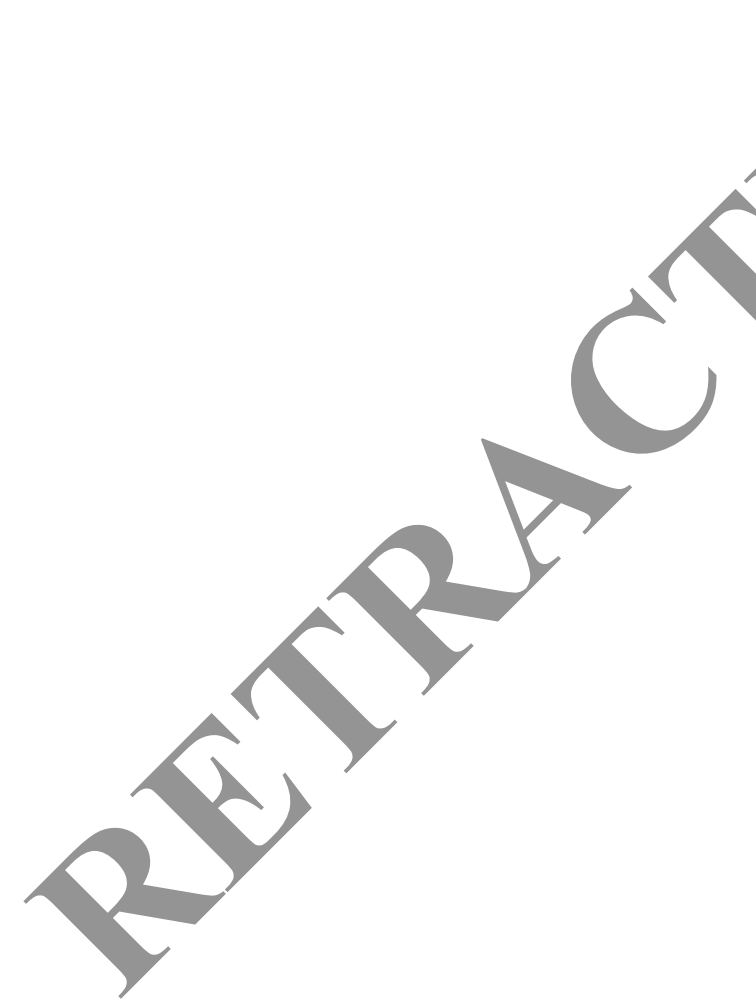

Ready to submit your research? Choose BMC and benefit from:

- fast, convenient online submission

- thorough peer review by experienced researchers in your field

- rapid publication on acceptance

- support for research data, including large and complex data types

- gold Open Access which fosters wider collaboration and increased citations

- maximum visibility for your research: over $100 \mathrm{M}$ website views per year

At BMC, research is always in progress.

Learn more biomedcentral.com/submissions 